\title{
90
}

\section{An Architecture for Robot Off-line Programming of Filling Welds for Multipass GMA-Welding of Pipe Branches}

\author{
J.K. Lauridsen, O. Madsen, H. Holm \\ Denmark \\ Phone: +4598154211/2959 \\ Fax +4598153030 \\ Email:i9jkl@iprod.auc.dk
}

Department of Production, Aalborg University

Fibigerstraede 16, DK 9220 Aalborg East

\begin{abstract}
This paper presents an architecture of an off-line programming system for generation of robot programs for welding the filling welds in pipe branches. The paper outlines the need of process models and how the structure of such process models must be in order to obtain the required quality to the pipe branch welding. Furthermore it is shown, how the process models are used to generate the control variables, so that the required quality to the pipe branch weldings is obtained.
\end{abstract}

\section{Keywords}

process modelling, off-line programming, robot welding

\section{INTRODUCTION}

In a large number of industries the joining of nozzles attached perpendicular on large diameter (see figure 1) pipes involves many labour intensive manual operations which impose high demands to the skills and concentration of the operator. Because of the significant requirements to the humans involved and the high demands to welding flexibility, automation by robots of this type of welding offers a great potential for many industries to improve welding productivity and in particular to improve welding quality.

However, there are only few reports on automatic robot based methods for this kind of welding. The reasons behind this are:

1. The path to be followed by the welding torch forms a complex so called "saddle type" curve.

2. Multi-pass welding is necessary. 
3. The welding position and the welding seam profile constantly change along the welding seam.

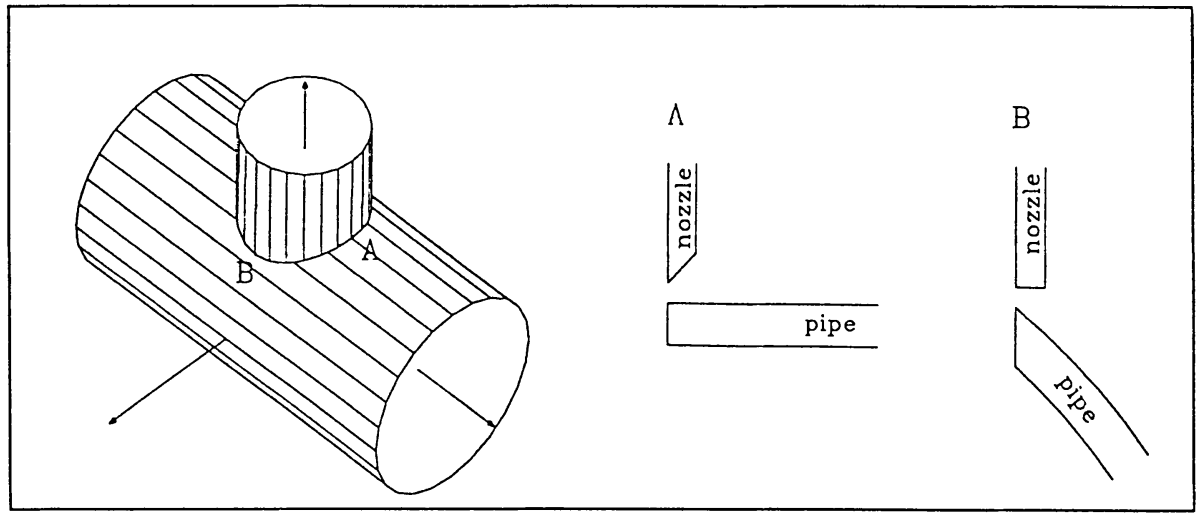

Figure 1. Sketch of a pipe branch. The diameter of the pipe is approximately $400 \mathrm{~mm}$ and the length is approximately $800 \mathrm{~mm}$, and the wall thickness is approximately 8 $\mathrm{mm}$.

Due to these reasons programming of robots with conventional on-line techniques becomes very cumbersome, and makes practical application almost impossible. One way to conquer this problem is to automate the programming task.

Automation of the programming of such a complex welding task implies a sensor based programming system, which must contain the following elements:

- Computer based models of the physical welding equipment.

- Computer based models of the physical welding process

- Computer based models of the physical workpieces to be welded.

- Computer based strategies and algorithms for planning the welding task.

- Computer based models of sensor control.

The computer based models are capable of matching the reel world into a computer world, by which the information needed for off-line generation of the robot program are extracted. The models of the welding equipment (i.e. geometric and kinematic model of the welding robot and workpiece manipulator, geometric model of the welding torch) and the workpiece can relatively easy be established in commercial available software packages.

This is, however, not the case with the computer based models of the physical welding process. These are models, that describe the relations between the control variables (i.e. the torch position, orientation, welding velocity, wire feed speed etc.), the joint geometry, and the desired weld quality.

Furthermore, the computer based strategies and algorithms needed for planning the welding task and off-line generation of the robot program, are not presently available.

Consequently, considerable effort must be placed in the following fields: 
1. Establishment of computer based welding process models, that are capable of describing the relations between the control variables, the joint geometry, and the desired weld quality. Since the dynamic structure and the quality requirements to the root bead in the pipe branch weldings differs significantly from the filling welds, it is necessary to operate with two different type of welding process models.

2. Elaboration of computer based strategies and algorithms needed for planning the welding task and off-line generation of the robot program.

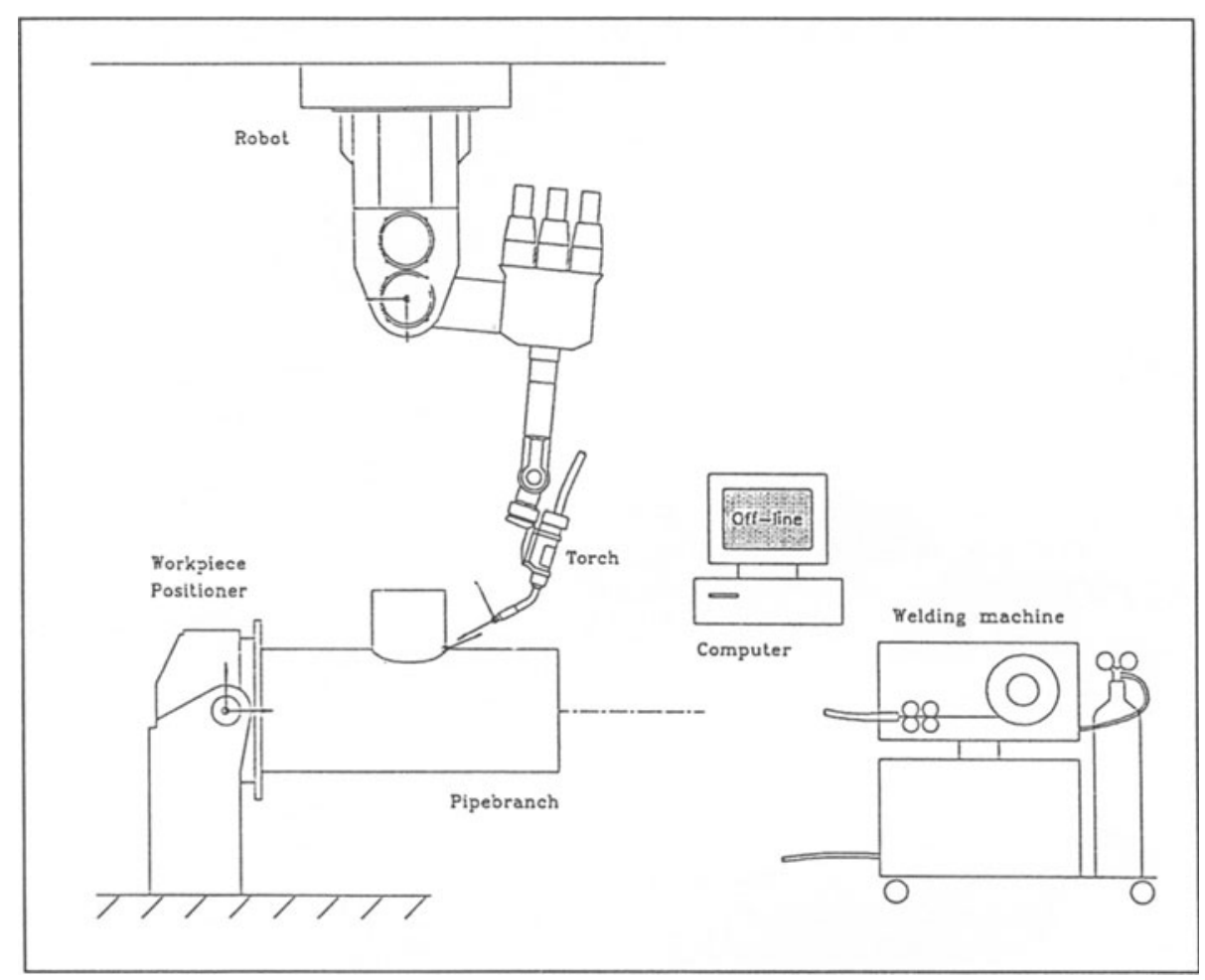

Figure 2. Outline of welding cell.

In corporation with Odense Steel shipyard, Denmark, the Department of Production, Aalborg University, has started the development of the mentioned computer based programming system (see figure 2). The work is primarily concentrated on the above mentioned fields.

In the last year, considerable results have been obtained in research in the above fields, (see. Lauridsen 1991, 1995, Madsen 1992, 1993, 1994 and 1995). Particular, results have been obtained in the field of root bead welding, so that it now is possible automatically to off-line program the welding of the root bead in a pipe branch.

This paper presents the results obtained so far on the establishment of an off-line programming system for robots for carrying out welding of the filling welds of nozzles attached perpendicular on large diameter pipe. 


\section{DESCRIPTION OF THE WELDING TASK}

Since the nozzle is attached perpendicular to the main pipe, the intersection curve between the inner radius of the nozzle and the outer radius of the pipe forms a saddle curve. Normally, when a specific welding task is considered, a number of cross sections of the workpiece along the welding axis is constructed. In this case particular case, the cross sections are created along the intersection curve between the nozzle and the pipe, so that the tangent to the intersection curve are normal to the plane, in which the cross sections are constructed.

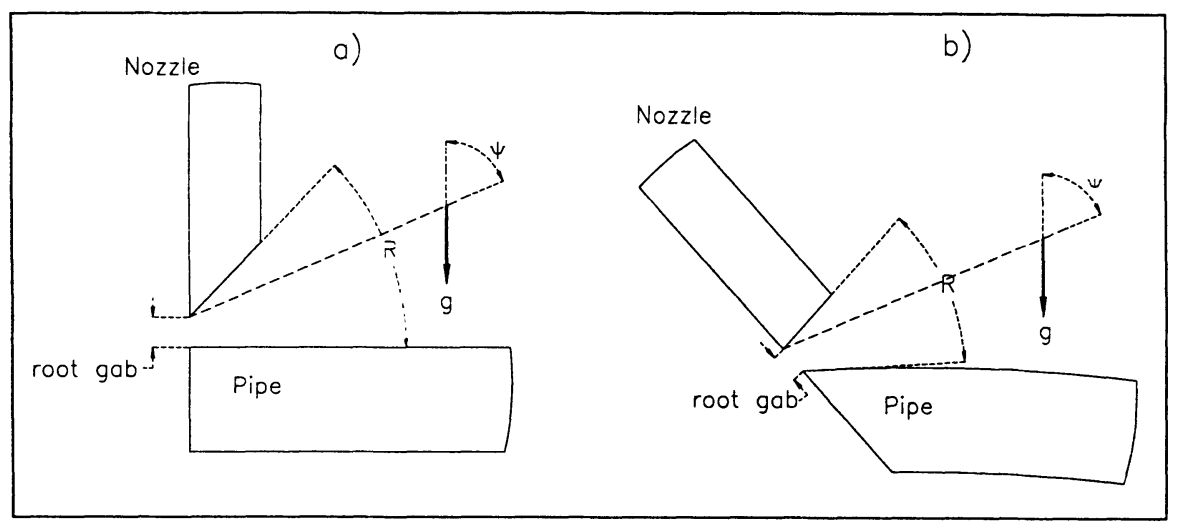

Figure 3. Cross sections along the intersection. a) is a cross section in position $\mathrm{A}$ of figure 1 and $b$ ) is a cross section in position $B$ of figure 1 .

By using the equipment setup as shown in figure 2, and in particular the use of a workpiece manipulator one important advantage is obtained. If it is assumed that the centreline of the main pipe is parallel with the axis of rotation of the manipulator, then for any position on the intersection curve, a value of the axis of rotation of the manipulator can be determined, so that the tangent to the intersection curve is perpendicular to gravity. (see Lauridsen, 1994). Furthermore, if the angle $\mathrm{R}$ in figure 3 is constant alone the intersection curve (this is at Odense Steel Shipyard obtained in production by using a numerical controlled flame cutting machine), then the angle $\Psi$ between the groove bisector and gravity is constant along the entire intersection curve. This means, that using a workpiece manipulator, the welding orientation along the entire intersection curve is constant.

However, the welding task cannot be considered as constant, because the mass distribution along the intersection curve changes, and changes from 2 to $5 \mathrm{~mm}$ in root gab must be expected. Furthermore, from figure 4 it is seen, that the free groove area, in which the filling beads are to be deposited changes along the intersection curve.

\section{THE OFF-LINE PROGRAMMING TASK}

Since off-line programming of the root bead welding has been realised, the programming task to be described here concerns the filling welds only. This off-line programming task is to generate a program for robot, manipulator and welding machine, so that the required welding 
quality of the finish weld is obtained, when the program is executed. The program is a trajectory of position, orientation and velocity of the end-effector for the robot, arc voltage and wire feed speed for welding machine and rotation angle of the workpiece manipulator.

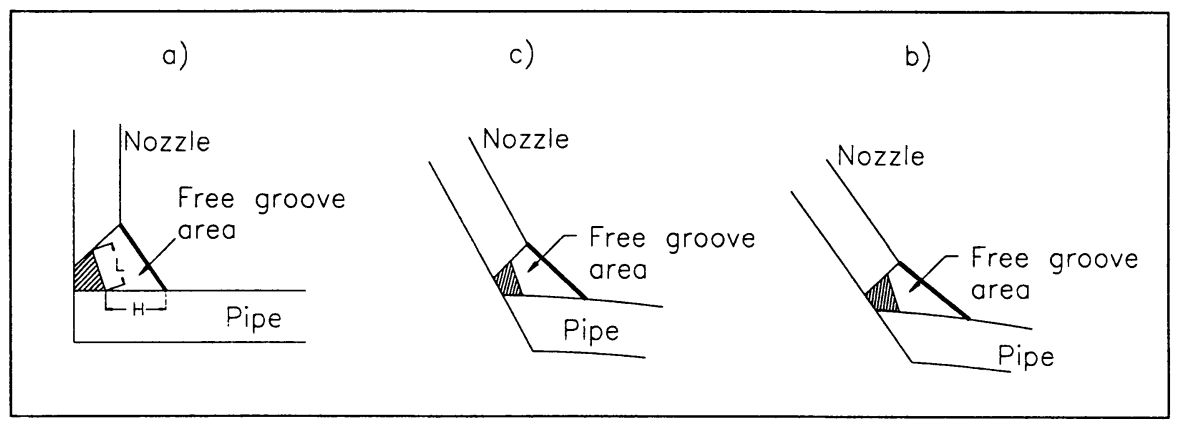

Figure 4. Free groove area along the intersection curve. a) is a cross section in position A of figure $1 . b$ ) is a cross section in position $B$ of figure 1 and $c$ ) is a cross section somewhere in between. The hatched area indicates the root bead, and the filled line indicates the required quality of the finish weld.

In order to generate the trajectory is it necessary to be able to compute the $4 \times 4$ transformation matrices of equation (1), and the corresponding velocity, arc voltage and wire feed speed.

${ }^{\text {base,robot }} \mathrm{T}_{\text {torch }}={ }^{\text {base,robot }} \mathrm{T}_{\mathrm{g}} \cdot{ }^{\mathrm{g}} \mathrm{T}_{\mathrm{p}} \cdot{ }^{\mathrm{p}} \mathrm{T}_{\text {torch }}$

Where base,robot $T_{\text {torch }}$ represents the location of the torch relatively to the base of the robot.

${ }^{\text {base,robot }} \mathrm{T}_{\mathrm{g}}$ represents the location of the g-frame (see figure 5) relatively to the base of the robot.

${ }^{\mathrm{g}} \mathrm{T}_{\mathrm{p}} \quad$ represents the location of the $\mathrm{p}$-frame relatively to the g-frame.

${ }^{\mathrm{p}_{\mathrm{T}}} \mathrm{T}_{\text {torch }} \quad$ represents the location of the torch relatively to the $\mathrm{p}$-frame.

The first matrix on the right hand side of equation (1) is a function of the workpiece shape and work cell layout. How this is computed is described in Lauridsen (1994).

The second matrix, which describes the location of the p-frame relatively to the g-frame, is a function of the root bead shape only. Consequently, this matrix is a result of the root bead welding, and can be derived here from (Madsen (1994) and Lauridsen (1995)).

The third matrix describes the position and orientation of the torch relatively to the pframe. In order to compute this matrix, the control variables for welding the filling beads are needed. These control variables are torch position, orientation and velocity (including weaving variables) relatively to the $\mathrm{p}$-frame, wire feed speed, and welding voltage. In figure 5 and figure 6 the definition of a number of the torch position and orientation control variables is shown.

In order to generate these control variables, welding process models of the filling beads are required. 


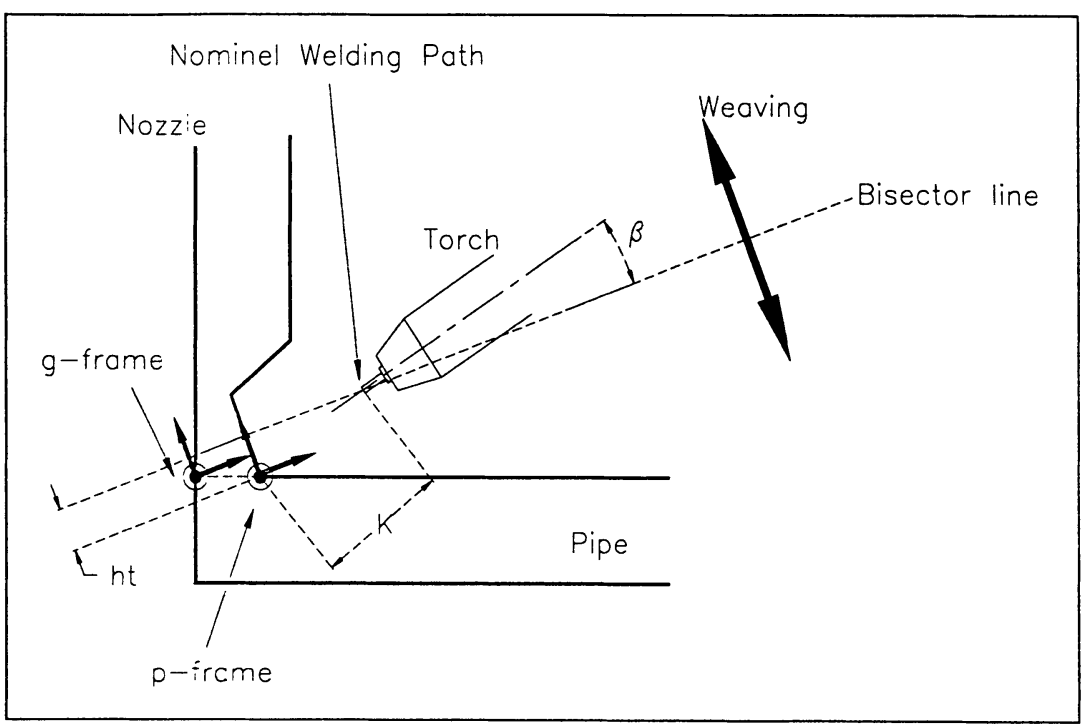

Figure 5. Definition of control variables.

\section{THE PROCESS MODELS}

As mentioned earlier, a process model describes the relation between the control variables and the joint geometry and the desired weld quality. In a mathematical way, this can be expressed as:

control variables $=f($ joint geometry, weld quality)

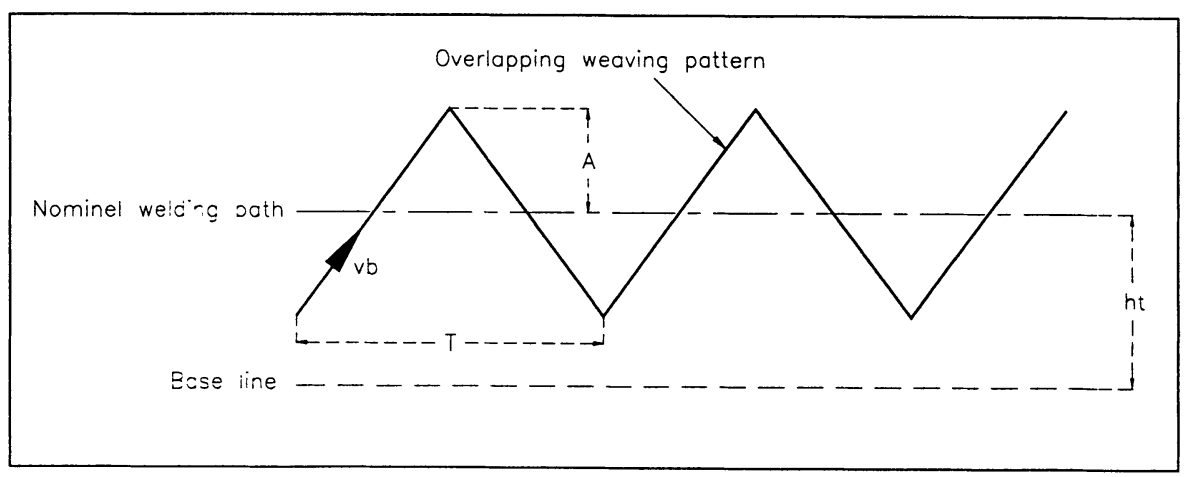

Figure 6. Definition of weaving pattern. 
As indicated in figure 4, the joint geometry changes along the intersection curve. However, since the resulting root bead geometry is known, and since the desired quality is known, the free groove area (FGA) and the variables $\mathrm{L}$ and $\mathrm{H}$ in figure 4 is known along the entire intersection curve. Consequently, the process models needed for planning the filling beads become functions as:

control variables $=\mathrm{f}(\mathrm{FGA}, \mathrm{L}, \mathrm{H})$

Given the dimensions of the pipe and nozzle as indicated in figure 1, the required quality of the finish weld can only be obtained by depositing two filling beads into the free groove area. (see figure 7). This means, that a process model for bead 2 in figure 7 and a process model for bead 3 is required.

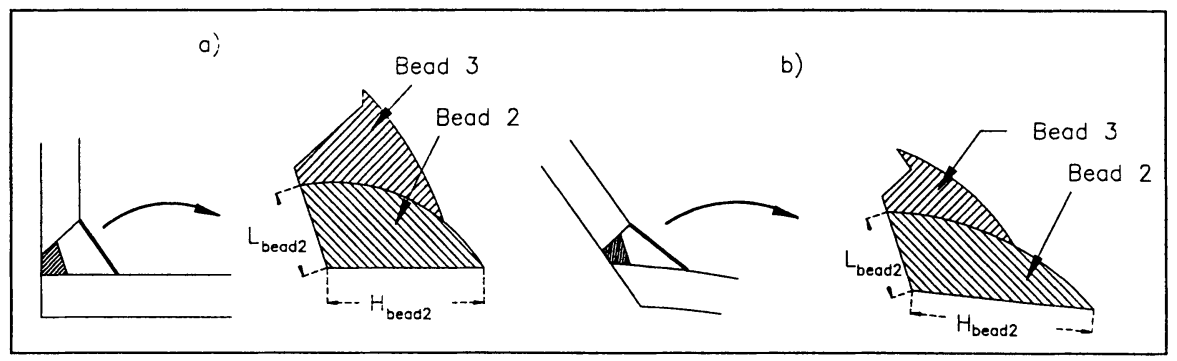

Figure 7. Free groove area with 2 filling beads.

The requirement to the quality of bead 2 must satisfy equation (2).

$\mathrm{L}_{\text {bead } 2} \leq \varepsilon_{1} \cdot \mathrm{L}$, where $\varepsilon_{1}$ is approximately 0.7

$\mathrm{H}<\mathrm{H}_{\text {bead2 }}<\varepsilon_{2}+\mathrm{H}$, where $\varepsilon_{2}$ is $2 \mathrm{~mm}$

The requirement given i equation (2a) is determined because the resulting geometry of bead 2 cannot be considered isolated, but must be determined so that the it is possible to weld bead 3 . The requirement given i equation ( $2 b)$ is determined by the required surface of the finish weld.

Experiments show, that it is possible to obtain the required quality for bead 2 only by changing the weaving amplitude $A$ and the value of $h_{t}$, as a function of $L$ (see figure 4) and keeping all other control variables constant. $h_{t}$ describes the distance of the center of weaving relative to the $\mathrm{p}$-frame. Consequently, the process models for bead 2 is on the form

$\mathrm{A}=\mathrm{f}_{1}(\mathrm{~L}, \mathrm{H})$

$\mathrm{h}_{\mathrm{t}}=\mathrm{f}_{2}(\mathrm{~L}, \mathrm{H})$

The process model for bead 3 is more complicated, because the expected shape of bead 2 must be taken into consideration. This means, that two conditions must be satisfied. Firstly, the cross section area of bead 3 must satisfy equation (4)

Area $_{\text {bead } 3}=$ FGA-Area bead $2_{2}$ 
This equation can be satisfied by proper selection of the relation between wire feed speed (W) and travel speed (v). Secondly, the area of bead 3 must be distributed properly in order to reach the required quality of the finish weld. This can be obtained by proper adjustment of $\mathrm{A}$ and $h_{t}$. Consequently, the process models for bead 3 is on the form:

$h_{t}=f_{3}(L, H)$

$A=f_{4}(L, H)$

$\mathrm{W}, \mathrm{v}=\mathrm{f}_{5}\left(\right.$ Area $\left._{\text {bead } 3}\right)$

\section{USE OF MODELS}

As indicated in section 3, considerable amount of the information used and generated during the off-line programming of the root bead can be reused when doing off-line programming of the filling beads. In figure 8 is shown, how the information is reused, how off-line programming of the filling beads takes place, and how the process models of the filling beads are used.

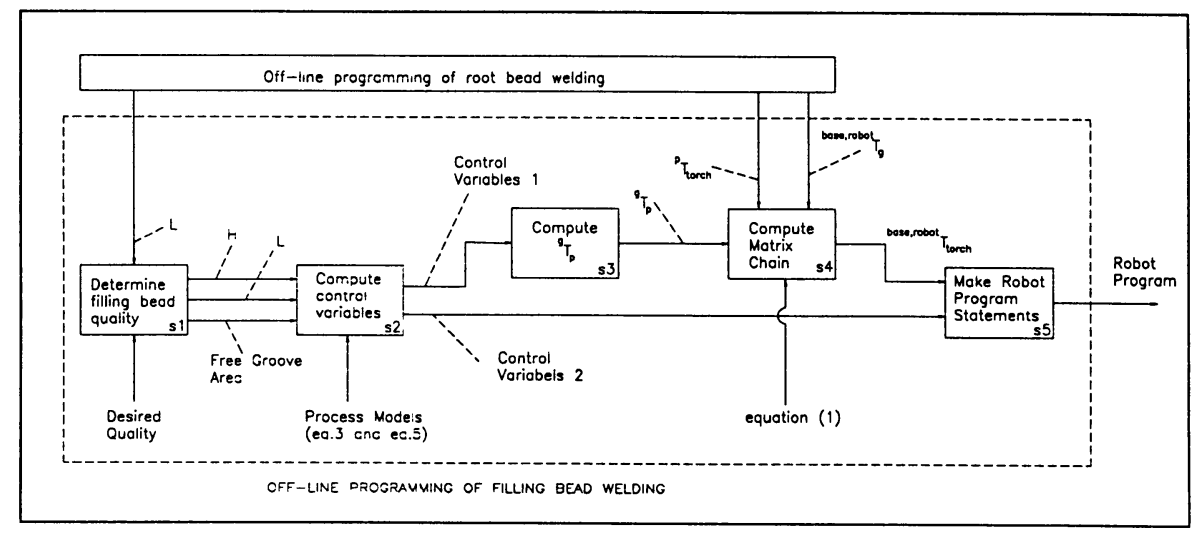

Figure 8 Off-line programming of the filling beads.

The top box of figure 8 illustrates the off-line programming of the root bead, whereas the bottom dashed box indicates off-line programming of the filling bead.

In $\mathrm{s} 1$, the free groove area and $\mathrm{H}$ is determined based on $\mathrm{L}$ (see figure 4), which is derived from the root bead and the desired quality of the filling bead. When the free groove area, $\mathrm{H}$ and $\mathrm{L}$ are known, the process models in equation (3) and equation (5) are used for generation of the control variables for bead 2 and 3 respectively. This is done in s2. The output of $s 2$ is two sets of control variables. The first set is variables related to position and orientation of the welding torch and are used in s3. The second set is the wire feed speed (W), the travel speed (v), the welding voltage, and the value of the axis of rotation of the manipulator. 
In s3 the matrix ${ }^{\mathrm{p}} \mathrm{T}_{\text {torch }}$ is computed based on the control variables, and in s4 the matrix chain in equation (1) is completed. In $s 5$, base,robot $T_{\text {torch }}$ is together with the second set of control variables used for making robot program statements.

Doing the sequence $(s 1-s 5)$ for a number of discrete steps along the entire intersection curve, yields the complete trajectory for robot, manipulator and welding machine, and the offline programming of the filling beads has been completed.

\section{CONCLUSION}

In this paper an architecture for off-line robot programming of filling welds for multipass welding of pipe of pipe branches has been suggested. The architecture is characterised by:

- The trajectory of a control vector, that controls the equipment (the workpiece manipulator, the robot and the welding machine) is generated off-line, based on the use of a model of the workpiece, which is going to be welding and on welding process models of the filling beads.

- A workpiece manipulator is used to position the workpiece so that the orientation of the welding seam with respect to gravity during welding is kept as described in a given control criterion.

Experiments performed so far indicates, that the suggested process models can be established, and consequently the suggested architecture forms an important contribution towards the realisation of and automatically programming system for welding pipe branches.

Currently, the architecture of the off-line programming system is being implemented in a prototype system at the Department of Production, Aalborg University, Denmark, and considerable efforts are put into the establishment of the suggested process models.

\section{REFERENCES}

Boelskifte, J. Hafsteinsson, I. (1994) Kinematic control for off-line programmed robotic root-pass welding of pipe branches. Department of Production, University of Aalborg, Denmark.

Galopin, M. Dao, T.M. Boillot, J.P. (1991) Design of optimum adaptation tables for robotic arc welding using vision sensing. In Proceedings of EUROJOIN, First European Conference on Joining Technology, Strasbourg, France, 5-7 Nov. 1991.

Holm, H. (1998) Off-line programming of robots for high strength welding of tubular joints. Main report from the ROPS-project, (In Danish).

Koguchi, T. (1990) Development of automatic welding method for large diameter nozzle attached to piping with GMAW. IIW Doc. XII-1162-90. July, 1990.

Lauridsen, J.K, Madsen, O. Holm, H. Hafsteinsson, I. Boelskifte, J. (1994): Model Based Control of a One Degree of Freedom Workpiece Manipulator for Welding of Nozzles. In Proceedings of EURISCON '94, European Robotic and Intelligent Systems Conference, Malaga, Spain, August 22-26, 1994

Lauridsen, J.K. (1991) Computer Aided Off-Line Programming of Multipass TIG-Welding. Ph.D. dissertation, Department of Production Aalborg University, Denmark, December. 
Lauridsen, J.K. Madsen, O. Holm, H.(1995) An Off-line Programming System for Welding the Root Bead in Pipe branches. Department of Production, Aalborg University.

Madsen, O. Lauridsen, J.K. Holm, H. Nielson, J. Schluter, F (1993) Model Based Control of a Workpiece Manipulator for Welding of Nozzles. In of Proceedings of: International Conference of Modelling and Control of Joining Processes, Orlando, USA, 8-10 December, 1993.

Madsen, O. (1992) Sensor Based Robotic Multi-Pass Welding. Ph.D. dissertation, Department of Production Aalborg University, Denmark.

Madsen, O. Lauridsen, J.K. Holm, H. Hafsteinsson, I. Boelskifte, J. (1994) Model of Root-Bead Welding for Off-line Programming and Control. Department of Production, Aalborg University

Madsen, O. Lauridsen, J.K. Holm, H, (1995): Control System Architecture for Robotic Welding of Tubular Joints. Department of Production, Aalborg University.

Miyake, N. (1980) Multipass welding of nozzles by an industrial robot. In Proceedings of 10th International Symposium on Industrial Robots, Milan, Italy.

Neerland, H. Aune, D. (1986) Evaluation of systems for robotic multi-pass welding". SINTEF-Report no. STF17 A86085, Norway. (In Norwegian).

\section{BIOGRAPHY}

$\begin{array}{ll}\text { Name: } & \text { Jan Kirkegaard Lauridsen } \\ & \text { M.Sc., Mechanical Engineering, Ph.D., } \\ & \text { Assistant Professor. } \\ \text { Affiliations: } & \text { Department of Production } \\ & \text { University of Aalborg } \\ & \text { Fibigerstraede 16 } \\ & \text { DK-9220, Aalborg East } \\ & \text { Denmark. }\end{array}$

I am employed as an Assistant Professor at the University of Aalborg, where I teach students in Mechanical engineering, primarily in the science of welding. Furthermore I am researching in control of welding, laying my main effort in the field of off-line programming of robots for carrying out multipass welding. I received my M.Sc.-degree at the University of Aalborg in 1988 in the field of welding High Strength Low Alloyed Steels. In 1992 I received my Ph.D.degree at University of Aalborg in the field of off-line programming of welding. 